\title{
WORKING WITH ATTENTION AND DISTRACTION \\ IN LEADERSHIP DEVELOPMENT
}

Accepted for publication: French, R., Sheffield, R. \& Simpson, P. (2019, in press)

'Working with Attention and Distraction in Leadership Development', Organisational and Social Dynamics.

\begin{abstract}
Bion's theory of groups is used to explore the dynamics of learning on a leadership development programme. The dynamic of a group is influenced by the capacity of its members to negotiate, consciously and unconsciously, the tension between the opposed tendencies of attention and distraction, which is related to the tension between a desire to learn and a hatred of the process of development. Bion's model of work-group and basic-assumption mentalities, which we equate with the dynamics of attention and distraction, is used to reflect on a two-month period of a development programme in a UK public service organisation. In related literature there is a tendency to focus on the pathology of basic-assumption mentality with limited interest in the healthy functioning of work-group mentality. Basic-assumption mentality contributes to understanding a group that is distracted from its purpose, but a focus on this, without comparable attention to work-group mentality, can lead to an inappropriately negative view of group process. This is contrary to Bion's essential optimism about the powerful psychological structure of work-group mentality. The paper demonstrates the importance of combining an analysis of both attention and distraction to fully appreciate the complex dynamic of groups engaged in a developmental process.
\end{abstract}

\section{Key Words}

attention, distraction, purpose, work-group mentality, basic-assumption mentality, leadership development 
In this paper we reflect on a two-month period of a UK-based leadership development programme through the lens of Wilfred Bion's theory of group functioning (1961) utilising his model of basic-assumption (ba) and work-group (W) mentalities. Bion's ideas have been shown to have value in relation to leadership development and practice (Simpson and French, 2005, 2006). This leadership development programme was designed and run by the authors for a public service organisation. It was established during a period of significant organisational change driven by a transformational reform agenda requiring public service organisations to provide 'more for less' and demanding institutional innovation to respond to increasing resource constraints. The impact of these reforms has been experienced at multiple levels, including the introduction of alternative organizational forms such as social enterprise, the challenge of reorganizing service delivery, and significant reductions in staffing levels. The requirement for managers to be able to lead work teams in increasingly creative ways with an awareness of business imperatives was influential in the design of the programme.

Central to our analysis of group work on this leadership development programme is a focus upon the group purpose. Purpose goes by many names: aim, core business, vision, mission, strategy, task, primary task, primary spirit, guiding spirit, intention, raison d'être, "knitting" (as in, "stick to the knitting"), and "talk" (as in, "walk the talk"), and we do not seek to attempt to differentiate between these various terms concerned with the intentionality of the group. Rather, our particular interest is in the detection of evidence of attention-to-purpose when dominated by work-group mentality and of evidence of distraction-from-purpose when dominated by basicassumption mentality.

Most of the literature that draws upon this theory tends to concentrate on basicassumption mentality (for example Lister, 2001; Seel, 2001; Stein and Pinto, 2011). By contrast, we focus on attention and distraction, work-group mentality and basicassumption mentality, in seeking to understand the dynamics surrounding learning and development within groups (French and Simpson, 2010). We believe that this better reflects Bion's essential optimism about the powerful psychological structure of work-group mentality.

Following an introduction to Bion's theory of group dynamics, we describe and analyse the responses of the group of middle managers on a leadership development programme. In particular, we explore the group dynamics that emerged after the group were presented with an unexpected challenge. The programme began as a relatively straightforward series of themed workshops. Half way through, however, the senior managers in the organisation approached the facilitators and said they were making $£ 20,000$ available to the participants to support projects that would take forward the strategy of the organisation. Participants' initial responses to this announcement included a mixture of shock, surprise and excitement.

We suggest that subsequent events demonstrated both basic-assumption and workgroup mentalities manifesting within the group as they struggled to respond to this new demand. Through our analysis of events we present an articulation of Bion's theory that encourages a more balanced treatment of work-group mentality alongside basic-assumption mentality than is typically the case. This analysis suggests some important issues for consideration in the design and facilitation of group learning events. It also suggests that Bion's confidence in the robustness of work-group 
mentality was justified and that we are generally well advised to place our trust in the innate human desire - and even need - for learning and development.

\section{Growth of Mind}

In Bion's view the texture of any group is influenced by two factors: firstly, by the forms of relationship, which he described as comprising dependence, pairing or fightflight; second, by the group's underlying mental and emotional state or, to use his term, the group mentality. It is the emotional tone generated by the mentality of the group which influence its capacity to address the tensions and difficulties that inevitably arise in relation to its purpose and internal relationships. The group mentality influences group behaviours, which consciously and unconsciously supports or undermines work on the group purpose.

Bion defined work-group mentality as attuned to the group's reality, including its purpose and its internal relations. Basic-assumption mentality, by contrast, is out of touch with the group's purpose and with the tensions of group life. This is sometimes described as an 'as if' mentality - the behaviour of the group suggest that it is 'as if' the group had a different purpose. Work-group mentality therefore supports the group's purpose, whereas basic-assumption mentality is, in effect, anti-purpose, because the group has, as it were, lost touch with reality. However, its members continue to behave as if they believe they are in touch.

Bion's work contributes to our understanding of leadership development through a focus on internal mental processes, specifically growth of mind through the process of thinking 'new thoughts'. He argued that the capacity to make oneself available for new thoughts, or 'the capacity for mind', as he terms it, 'depends on the capacity of the unconscious - negative capability. Inability to tolerate empty space limits the amount of space available.' (Bion 1969, p. 304) The specific nature of this 'empty space' will depend upon context, but it might, for example, be conceived of as an absence of thoughts or ideas. From such a perspective learning and development occur through the discovery of thoughts as ideas, emotions and/or actions that are appropriate for the particular purpose of the individual or group. An inability to tolerate 'empty space' may result in the adoption of thoughts that are not fit for purpose or are even anti-purpose. Bion was interested in growth of mind, which can require waiting in order to allow for the emergence of thoughts that are fit for purpose (Simpson and French, 2006).

Bion's writings on the psychoanalytic process have made a significant contribution to our understanding of the development of the capacity to think. In their book on Bion's clinical thinking, Symington and Symington (1996, p. 3) write that the 'only assumption' (their italics) underlying Bion's theorising on this was that 'the mind grows through exposure to truth', or, as Bion put it, 'truth seems to be essential for psychic growth' (Bion, 1962, p. 56). By growth of mind, he meant the ability to act more consistently and rigorously in relation to truth; and by truth he was referring to the psychic reality experienced by the thinking individual in the here and now.

Of particular relevance to our discussion of the experience of the managers on this programme, faced with an unexpected challenge, is his emphasis on the centrality of notknowing (French and Simpson, 1999, 2001; Simpson, 2010) in the process of thinking. Somewhat provocatively, he believed that knowledge can be part of the disease, which 
led him to be particularly interested in the impact of transformations into knowledge from the unknown. His belief was that not-knowing is the precondition for new insight. In contrast, existing knowledge, in the form of models and theory can merely help us 'to avoid having to do any more thinking' (Bion 1978, p. 6). Underlying Bion's work was the conviction that real learning and development can occur at the edge of knowledge, where the experience and fear of catastrophe meet the containing possibilities of faith (Eigen 1981, 1993, 2014; French and Simpson, 2001; Simpson 1997).

The state of not-knowing is, however, a challenging and, sometimes, threatening experience. As well as providing the stimulus for insight, it can also be an uncomfortable and difficult place that can provoke a compulsive desire to re-assert control of the situation and to engineer a more comfortable space. This approach to learning and development can be difficult as a result of our well-developed habits of self-protection and self-provision that constitute the flight into comfort and control. It is an approach that requires practice, therefore, and involves the development of the state of mind that Bion, following John Keats, called 'negative capability' (Bion $1984 b$, p. 125). This has been argued elsewhere to have potential relevance for leaders and managers in situations of organisational change and uncertainty (Saggurthi and Thakur, 2014; Simpson, French and Harvey 2002).

\section{Case Part 1: An Unexpected Development}

This leadership development programme for 13 middle managers ran weekly over a 6 month period and involved 15 days of workshops. Following a very clear brief from the client organisation, this was designed to be an intensive programme covering many different topics, such as Leadership Style, Presenting with Impact, TeamBuilding, Recruiting Staff, and Performance Management. Also at the insistence of the client, an early start date was set for the programme. Acceptance on to the programme required participants to commit to the pre-published schedule of workshops, prioritising attendance over other commitments. The programme was led by Rob (co-author), who delivered or co-delivered the majority of the workshops, with a team of specialists contributing to certain workshops.

Two months into the programme, Rob met with one of the Directors and the organisation's Programme Coordinator, a management trainer. The Director started by saying she wanted to add an important new dimension to the programme, requiring participants to consider broader 'good practice' imperatives when asking for funding for 'improvement ideas'. This had been identified as a key organisational development that would contribute to the organisation's emergent change strategy. To demonstrate that this was an important development she said that she would make $£ 20,000$ available for the implementation of any ideas the group could come up with that would benefit the organisation as a whole. It was agreed that the group would present their ideas for evaluation to this Director and the Chief Executive. An additional condition was that the money had to be spent or committed by the end of the current financial year - which was only four months away.

The implementation of this proposal required several amendments to the programme, in particular adjusting the design of two workshops to allow time to work on the proposal, as well as to learn about appropriate tools, techniques and concepts. The date set for the presentations was two months away, replacing a third workshop. 
However, the original date for that event was also changed to fit with the diaries of the two senior managers.

This new development was introduced to the group at the next scheduled workshop, which fortuitously happened to focus on Creative Problem Solving. The day had been re-designed to provide tools and models of specific relevance to working on the new challenge of developing improvement ideas. The participants now had just six weeks before Presentation Day, with one further workshop in two weeks to further develop their ideas.

Rob had mixed feelings about the change, welcoming the injection of energy and excitement generated by this intrusion of 'commercial reality' into the programme but wondering if it was constructive to introduce it at such a late stage in an unplanned and sudden manner. For the two months of the programme up to this point Rob had been working hard to engage participants in the learning process in order to increase its potential to be relevant and useful. There had been little time between the sessions for participants to reflect upon their learning and to try it out in practice. Too much material and content were getting in the way of working more responsively with participants' learning and role needs. He had been trying to engender a sense of power and agency in their actions but appeared to have achieved only limited success in this and Rob wondered if this was because the group simply welcomed the pattern of being 'fed' information without having to take any learning risks.

From the initial stages of the programme he had been concerned by how quickly the group had developed a habit of passive engagement with the learning process and a high level of dependence upon the facilitator and the programme itself to 'deliver learning'. The capacity to engage creatively with risk - the inevitable risk that accompanies any engagement with the unknown - had seldom been demonstrated up to this point.

Further, many participants were feeling increased pressure at work because of the programme demands. They had been given notice of the workshop schedule, but they believed that, because of the hurried start to the programme, this had not been sufficient. A growing level of anxiety and resentment had built up around this. The response of the Programme Coordinator was to insist, at times forcefully, that attendance was mandatory. No Discussion. No Exceptions.

In terms of Bion's framework, this intervention by the senior managers of the organisation introduced a new psychic reality. A key question at the time was, 'Can the group respond to this challenge for development with growth of mind, or, conversely, will they resist this opportunity for growth?' As we will see later, the intervention was experienced, by some at least, as a threatening experience. At the individual and group levels there was evidence of distraction but also of attention, with the exercise of negative capability which seemed to lead to learning and development.

\section{Attention and Distraction}

Before recounting in more detail, the impact of the new proposal on the course participants, we will return to Bion's theoretical framework in Experiences in Groups 
(Bion, 1961). He proposed that a group will operate simultaneously in two ways strictly contrasting, but both always present in potential at least - with one tending to dominate group process at any particular point in time. These he called, 'work-group' and 'basic-assumption' mentality and functioning. Some care is needed in the use of these terms as it is not uncommon for writers - even Bion himself on occasion - to refer to 'the work-group', giving the impression that they are referring to a particular type of group, when in fact Bion intended the phrase to refer only to one of the two mentalities that operate within a group. It is partly to avoid the resulting confusion that we have taken on instead the terms attention and distraction.

Attention describes the disposition and dynamics that characterize the life of a group which is able to manage its own internal tensions, anxieties and relationships in such a way that it is able to remain attentive to its agreed purpose and therefore to function effectively. Distraction, by contrast, describes the state of a group that has lost touch with its purpose and - generally without even realising it - become caught up in an 'unconscious group collusion' (Eisold, 2005, p. 359), namely, that something else needs doing first, an 'as if' purpose' - as if this something else must be achieved before the actual purpose or task can be properly addressed.

The key difference between these two mentalities is not rationality or irrationality but rather the group's relationship to 'the psychic reality of the task' (Armstrong, 2005, p. 145). Elsewhere Bion uses the term 'truth' in a manner synonymous with 'psychic reality'. The proposition that 'truth is growth-promoting and anti-truth psychically debilitating' (Symington \& Symington, 1996, p. 114) could be read as a direct summary of this framework. Attention seeks exposure to truth, even if this implies postponing pleasure and accepting pain, and for Bion, exposure to truth promotes 'a capacity for understanding' (Bion, 1961, p. 161) and leads to development and learning; it is a 'developmental achievement' (Armstrong, 2005, p. 142). Distraction, by contrast, is rooted in resistance to learning and development, its comfort lying in the fact that it 'will not demand any painful sacrifices' (Bion, 1961, p. 128).

Learning and development are therefore central to attention and are a key element of human nature. We are 'hopelessly committed to a developmental procedure' (Bion, 1961, p. 89); we have 'a compulsion to develop' (Bion, 1961, p. 161). This commitment-compulsion is explored in detail by Armstrong, who shows development to be pivotal in differentiating these two states of mind, which are, fundamentally, contrasting experiences of development that echo throughout Experiences in Groups:

There is neither development nor decay in basic-assumption functions, and in this respect they differ totally from those of the work-group. (Bion, 1961, p.

... basic-assumption mentality does not lend itself to translation into action, since action requires work-group function to maintain contact with reality. ( $\mathrm{p}$. 157)

Thus, attention gains its particular resonance from engagement with truth; that is, the readiness and the capacity to face the psychic realities of group purpose and group membership and the tension between shared intention and individual differences. Lawrence et al. (1996, p. 30) suggest that the major 'inputs' to the establishment and maintenance of attention are 'people with minds who can transform experiences'; the resulting outcomes are insight, understanding, learning, growth, and development. 


\section{Case Part 2: Losing a Sense of Purpose}

Rob was the trainer who led the workshop on Creative Problem Solving. He started with an outline of the day and the formal announcement that the day would focus on the development of 'improvement ideas'. This was the first time the group had heard this face-to-face. Senior management sponsorship and funding for the implementation of these ideas added another dimension to the reality of the programme - a reality that now contained higher levels of visibility; where powerful others might observe and evaluate the outcomes of their endeavours.

The workshop began with feedback on a questionnaire on preferred problem-solving styles. Having emphasised the benefits of diversity for aiding novel thinking, the group were asked to generate a list of potential improvement ideas. This part went quite quickly. There was some apprehension in the room around the nature of the challenge, but the group appeared to work effectively at this stage. Individuals were then asked to choose to work on an idea that they found interesting. This took up until lunch by which time people had formed into three distinct groups.

In the afternoon, the groups were given further guidance on the creative problemsolving process. The groups then moved to different rooms to start working on their improvement idea. Both groups downstairs found the process quite stimulating. There was high energy in Group 1 (5 people) and lots of laughter. This group tried one of the techniques that had been introduced in the morning and it appeared to aid their ability to focus on the problem before generating solutions. Group 2 ( 2 people) was working at a steady pace, making progress, but lacking the vitality, enjoyment and learning of Group 1. Group 3 (6 people) was very different. When Rob walked into the room, emotions were running high:

Trevor (a group member) tries to persuade the group, "Come on, we've got to try and get something done..." Susan, smiling unconvincingly, looks bemused and embarrassed by whatever is going on. Suddenly Mary says: "How can they make us do this?" She is furious. She then says: "Look, it's best if I don't join in any more..." She sits back and is silent for the next 30 minutes, until the group has a tea break.

During Mary's quiet time, Trevor and Susan are trying frantically to keep the group focused on action. The impression is of two people unable to sit still, desperately trying to make something happen; anything better than nothing. There is no reflection in the group, merely unrelenting physical activity, driven by Trevor and Susan, as they take turns at the flip-chart and try to orient the group towards some kind of productive work.

Stephen and Michael are quiet and making no discernible contribution. Valerie is trying to keep positive with occasional attempts to calm the group and reduce the anxiety, but she is less than convincing and appears to be in a state of shock.

Rob observed that the group was not utilising the earlier learning on creative problemsolving models. In a later evaluation of this part of the programme, Trevor said: "My group never got our heads around the creative problem-solving process - I really don't know why that was. We may have been too anxious about finding an idea but we could not focus."

They were striving to make progress but without any clarity of purpose. There was a skittish, brittle energy, focusing on the idea itself, without any sense of attention to the 
way the group was working. They seemed simultaneously to experience embarrassment, shock, surprise, anxiety and determination, but without the will and/or the wherewithal to ask for help or to stop and reflect. They did not know what to do about Mary's outburst or how to work with her. At this point the group chose to take a break for tea.

At the end of the day, Rob brought together the 3 separate groups into one large group, to review the events and learning of the day. This was both pre-planned, and done with a new-found purpose, from Rob's view: to achieve a distancing for some group members from the distracting emotions of the earlier work.

In the review session, the groups shared with each other their experiences of group working from the day, and their reactions to the introduction of the improvement ideas task. Having had some hours to process this latter point, considerable anxiety was expressed not only about the task but also about aspects of the process.

This discussion was led strongly by Group 3 and included a number of questions that they felt unable to answer:

Are the senior managers assessing our presentation style or the ideas, or both?

Is this like the Dragon's Den ${ }^{1}$ ?

Is it pass-fail?

What if we come up with ideas that require a lot of work to implement?

We already have full-time jobs - how would we find the time to do it?

What are the Director and Chief Executive like?

How career-limiting is this exercise likely to be?

Group 1 reported that they had a genuinely enjoyable time and were surprised to hear about the more difficult experience of Group 3. The whole group experience gave a further opportunity to experience the contrasting tensions of attention and distraction.

The session ended with the groups deciding that the next step was to take their ideas back to the workplace to check on their viability.

A few days later Rob heard by e-mail from the Programme Coordinator that Mary had decided to leave the course "for personal reasons". On day one of the programme she had said: "I'm not sure I want to be here in all honesty... I started a new job last week, and that's where my mind is." Mary had noticeably had a difficult time in fitting in the demands of this course, even before the Creative Problem-Solving workshop. Michael, a member of the same group, who was very quiet in that afternoon session, had e-mailed the Programme Coordinator to ask to be moved from the group with the complaint, "They didn't listen to me." He was also considering leaving the course, but the Programme Coordinator persuaded him to stay.

\section{A Group Dominated by Distraction}

Bion's most basic insight was that sometimes a group works sufficiently well to manage its tasks and its own dynamics and relationships, while at other times group

\footnotetext{
${ }^{1}$ The Dragon's Den is a television programme in the UK in which entrepreneurs seeking funding present their product innovations (cf Improvement Ideas) to a panel of Venture Capitalists, who make a pass/fail or fund/reject decision. The Dragons are very direct and sometimes punishing in their critique.
} 
members become distracted from their purpose and their energies are dispersed into alternative emotions, thoughts and actions (see Needleman, 1990). He suggested that these 'obstructions to work-group activity' (Bion, 1961, pp. 145-6) find expression in three forms of interaction - or patterns of behaviour' (p. 175) - that 'appear to be fairly adequately adumbrated by three formulations, dependence, pairing, and fighting or flight' (p. 188). Following Bion, these states are generally called 'the basic assumptions' and are expressed in the abbreviations, baD, baP and baF.

Group 3 appears to have been dominated by basic-assumption fight/flight (baF), where senior management were perceived as persecutory and powerful enemies. The major defense associated with this mentality involves the splitting off and projecting outward of intra-group sources of anxiety and aggression. Mary initially expressed 'fight', later followed by 'flight', both within the group, by withdrawing from participation for half an hour, and later still by withdrawing from the course entirely. Michael and Stephen also effectively removed their contribution at the time - in flight from the task and/ or the group - and both subsequently changed groups, Stephen joining Group 2, Michael Group 1.

Trevor and Susan's behaviour in trying to 'rally' the group appears to be a form of panic, one of the classic affects operating in baF mentality. They manifested a secondary defense in denying aggression and failing to engage with Mary's difficulties. While they managed to generate a form of activity there was little genuine sense of optimism and hope. They demonstrated the characteristics of distraction, dispersing their energies into physical activity, as did the withdrawal of Mary, Michael and Stephen, although Mary's fury and their silence also gave voice to the dispersal into emotion.

The latitude given to the group by having the opportunity to choose their own ideas and to develop these, albeit under time pressure, was perceived by some as exciting but by others as an extra burden. This aroused some feelings of persecution: "How can they make us do this?" as well as milder statements demonstrating stress: "How can we do this, as well as our day jobs?" For some, Mary especially, the extra demands imposed by the organisation's executive directors brought strong feelings to the surface.

The ongoing issues of meeting their commitments alongside a hastily-arranged leadership development programme began to 'bite' more sharply, and this newlyintroduced exercise proved the catalyst to express previously suppressed thoughts and feelings. As one participant said, in an end of course evaluation:

"The fundamental element of this part of the course was a surprise. No one expected it. It felt that members were already stressed by, for some, the short notice of attending the course and managing diaries which were pre-booked, together with heavy workloads. Therefore, adding the additional exercise compounded the pressure. It also seemed that the outline of the exercise became blurred and confused people. The purpose of the task and perceived expectations became inflated and distorted. Members seemed to feel they were going to be judged critically and that the initiatives had to be successful, when the real objective was to go through the process of building a business case. Therefore, the group projected their own level of discomfort, based upon a collective assessment of what the task held and the status of the judges. The information for the assessment being made up of a combination of fact and fiction, myth and emotion." 


\section{Attention to Purpose}

As mentioned in the introduction, there is a tendency in the literature and in practice, to utilise only one half of Bion's theory of group functioning, focusing predominantly upon groups distracted from their purpose and dominated by basic-assumption mentality. This does reflect the emphasis that Bion gives to basic-assumption mentality in Experiences in Groups, but we contend that this was not his intended emphasis. He wrote more on basic-assumption mentality because this was largely absent in the understanding of group dynamics at the time, whilst he believed that the means of giving attention to purpose in work-group functioning was already well understood and described by other theoretical frameworks.

In our recent practice we have found that greater balance in using Bion's ideas can be achieved by focusing first on the dominant form of interaction within the group rather than on the dominant mentality; that is, looking first for evidence of dependence, pairing or fight-flight, before trying to assess whether the group is dominated by ba or W functioning (French and Simpson, 2010). For example, our attention might be drawn to a dependent relationship. In such a case, we try not automatically to assume this to be basic assumption dependence, such as on a particular leader figure. Instead, we try to assess the evidence, in order to understand whether this dependent relationship points to attention or to distraction.

The three interactions identified by Bion - dependence, fight/flight and pairing appear to be fundamental to 'the social capacity of the individual' (Bion, 1967: 118). As humans, we have to interact the way humans do: we pair (P); we take a lead and we depend on others (D); we work with others and we also fight or run from them (F). What Bion's insight allows us to do is to recognise that these key interactions can manifest as either attention or distraction.

We represent this shift in emphasis in Table 1, which emphasises two aspects of our practice that are not commonly represented in the literature on Bion's work. Firstly, that the central issue is identification of the key interaction; and secondly, that workgroup mentality can be differentiated in relation to the three forms of interaction in just the same way as basic-assumption mentality.

\begin{tabular}{|cc|c|cc|}
\hline $\begin{array}{c}\text { State of mind } \\
\text { Attention }\end{array}$ & $\begin{array}{c}\text { Key } \\
\text { Interaction }\end{array}$ & & $\begin{array}{c}\text { State of mind } \\
\text { Distraction }\end{array}$ \\
\hline WD $\leftarrow$ & $\mathbf{D}$ & $\rightarrow$ & $\mathrm{baD}$ \\
$\mathrm{WF}$ & $\leftarrow$ & $\mathbf{F}$ & $\rightarrow$ & $\mathrm{baF}$ \\
$\mathrm{WP}$ & $\mathbf{P}$ & $\rightarrow$ & $\mathrm{baP}$ \\
\hline
\end{tabular}

Table 1: Identifying key interactions in $\mathrm{W}$ and $\mathrm{Ba}$ mentalities

By making the key interactions central in this way, we are not suggesting that they are somehow more fundamental than the states of mind. Rather, we see this as an essentially practical analytical device to evaluate whether the group is engaging with or resistant to - learning and development. Thus, one way to understand the particular state of a group may be to start with the question: "What is the key interaction here?" Only then would we ask: "What state of mind is reflected in the way the interaction is 
being 'used' by the group?" Does the emergence of a 'pairing', for instance, create distraction, in the form of an ungrounded 'air of hopeful expectation' (Bion, 1961, p. 151), which allows group members to lose concentration and focus and to pin their hopes on the outcome of this pair, while becoming passive themselves and uninvolved in the work? Or does the pairing stimulate attention, by helping group members to 'face the truth' and, as a result, to develop new ways of thinking and acting, to engage collectively in learning and development?

The tension between attention and distraction means that although one state of mind may dominate for a while the situation is never stable. The complexity of the factors involved - conscious and unconscious, individual, group and organizational, internal and contextual, structural and dynamic, task- or person-related - means that states of mind may shift with great speed and regularity, or they may become culturally embedded and long-lasting. Gilmore observed, in relation to productive pairs, that 'At one stage of a lifecycle a pair might be productive, yet later on the role might become stifling or anti-developmental' (1999: 3).

These suggestions remain tentative, but they do appear to allow scope for a more developed description both of the key interactions and of the forms that attention might take. Table 2 adds some descriptive categories both to the basic forms of interaction and to the forms they might take in both states.

\begin{tabular}{|l|c|l|}
\hline \multicolumn{1}{|c|}{$\begin{array}{c}\text { State of mind } \\
\text { Attention (W) }\end{array}$} & Key interaction & \multicolumn{1}{c|}{$\begin{array}{c}\text { State of mind } \\
\text { Distraction (ba) }\end{array}$} \\
\hline $\begin{array}{l}\text { friendship as a foundation } \\
\text { for thinking together }\end{array}$ & $\begin{array}{c}\text { Pairing } \\
\text { influence from two } \\
\text { people/ groupings }\end{array}$ & $\begin{array}{l}\text { idealized pair the source } \\
\text { of hope }\end{array}$ \\
\hline $\begin{array}{l}\text { leader authorised to guide } \\
\text { group thinking process; } \\
\text { role clarity }\end{array}$ & $\begin{array}{l}\text { Dependence } \\
\text { a single leader } \\
\text { plus } \\
\text { follower/s }\end{array}$ & $\begin{array}{l}\text { 'knowing' (all-knowing) } \\
\text { leader }\end{array}$ \\
\hline $\begin{array}{l}\text { us with them; } \\
\text { fighting for a purpose; } \\
\text { fierce struggle with an } \\
\text { imposed challenge; } \\
\text { active engagement with } \\
\text { difference }\end{array}$ & $\begin{array}{l}\text { Fight/flight } \\
\text { us and them }\end{array}$ & $\begin{array}{l}\text { us versus them; } \\
\text { just fighting - to win for } \\
\text { its own sake; } \\
\text { projecting anxiety onto an } \\
\text { out-group }\end{array}$ \\
\hline
\end{tabular}

Table 2: Key forms of interaction in Attention and Distraction

\section{Case Part 3: Losing a Dog but not the Plot}

Two weeks later a second redesigned workshop allowed the groups to continue working on their improvement ideas. Group 2, comprising Daniel and Margaret was now joined by Stephen (from Group 3). This group had functioned in a fairly pedestrian manner in the first workshop but now there was a greater energy and focus 
in their work. It became clear that Daniel and Stephen were a friendly pairing. From the start of the programme Rob had noticed that they would often leave sessions together and spend time together during breaks. Their work was characterised by laughter and confidence. Daniel was quite an original thinker, though less reliable on method and detail. Stephen and Margaret were more methodical and together they formed a well-balanced group. During the session, however, the group's time in developing their idea was limited because one of the groups, Daniel, had to leave early in the afternoon. A problem had emerged at home - his dog was lost! With his leaving, so, it seems, did much of the energy in his group.

Following this workshop, the groups seemed to make good progress in preparation for the Presentation Day. Each group had sent their one-page business plan to the Programme Coordinator and he, in turn, had sent it to the two senior managers.

When the day came for the presentations, it transpired that Group 2 had worked hard during the period since the dog went missing. On the day a sense of equanimity pervaded their work. The three members shared the responsibility of the presentation and their idea was judged the most novel by the two senior managers. The Director who had set up the improvement project later praised their presentation as being the best she had heard.

All of the presentations went well. The outcome was that each group's ideas were given a qualified "yes" - all needing more work for implementation, some more than others. The senior managers promised more than $£ 23000$ in funding, in excess of the figure originally offered. After the senior managers left, the participants relaxed, clearly relieved, surprised, tired, and proud.

The confluence of pressures brought a set of unconscious thoughts, emotions and themes to the surface. In the end-of-course review some group members asked if the intervention had been designed with a lack of clarity around the task to mimic real life. There continued to be a degree of suspicion in the group, a shadow of being observed and evaluated.

As a matter of methodological reflexivity, Rob sought to check the resonance of his emerging interpretations in two ways. First, in formal reviews, often at end of day, with the whole group. Group members would review their experiences of the day, and of the programme to date. They were often able and willing to share their own interpretations of the themes that were developing, around both group development and the formal, tasks of the programme. What became clear was that they, too, were experiencing the competing attractions of attention and distraction. They were managing these, often privately, and sometimes publicly, with help from each other, typically with humour and a wry recognition of the layered depth of the situation in which they had found themselves.

At times, for Rob, the anticipation of raising these issues with the large group brought too great a risk: might raising the themes provoke emotions which could generate further distraction? He sometimes spoke to people individually, to check the accuracy of his own interpretations, and to understand theirs. It sometimes seemed the safer option. 


\section{Development and Attention to Purpose in Work-Group Mentality}

If a group lacks the capacity to tolerate anxiety, then its members can be distracted from its purpose and basic-assumption mentality can dominate group functioning. We have seen how this manifested in one group, whose members plunged into the panic and chaos of basic-assumption fight/flight. However, we also see evidence in others right from the start in one group - of sustained attention to purpose with a stronger sense of work-group mentality and the resulting cooperation. Even though members of these groups experienced the pressure of a high workload and the confusion of an uncertain task that seemed to expose them to critical scrutiny from senior executives, they demonstrated negative capability - the ability to tolerate the 'empty space' of not-knowing in a manner that created a place for new thoughts to be entertained.

Throughout the case we see evidence of the facilitator's role in helping the groups to tolerate uncertainty. In the final phase this involved working to put participants at ease and to enable them to focus on the work already done. This is an example of workgroup dependency, in which the participants authorise the facilitators to hold some of their anxieties and to support and guide their thinking process. It is noteworthy that when Rob visited Group 2, when they were caught in baF mentality, he later reflected, "At the time, I believed that they did not want me to intervene in their work. There was a barely suppressed anger in the room and with some relief I judged that it was best not to confront them at this time." The domination of distraction - expressed as basic-assumption fight mentality - resisted the potentially containing function of work-group dependence that might have enabled them to hold an empty space for them to think and engage in learning and development.

In the final phases of the task we observe all three groups managing to conserve their energies rather than dispersing into anti-purposeful activity, emotion or explanations. It appears that time itself may offer a containing force leading to the emergence of negative capability. However, in this situation we observed that some individuals appear to think more effectively in the presence of others and, in particular, some in the company of particular friends. It is as though the complementary capacities for thought in the pairing generate pathways for new thinking that is present only in the pairing, but in neither individual when they are apart. This form of 'thought leadership' from a friendly pairing is an interesting example of fruitful areas for further research on the potential application of Bion's notion of work-group mentality through the analysis of key forms of interaction.

Overall, we observe not only the development of negative capability but also the related capacity to engage with risk - in a manner that had not been observed in the programme up to this point. With each group there is evidence of a growing capacity to manage its own internal tensions, anxieties and relationships in such a way as to enable it to function effectively. However, far from being an extraordinary phenomenon (as might be inferred from the level of anxiety experienced by some in the early stages), the achievement of these groups appears in a sense merely ordinary. In different ways, each managed to develop an effective relationship or engagement with 'the psychic reality of the task' (Armstrong, 2005, p. 145), precisely the 'developmental achievement' that Armstrong (2005, p. 142) describes as a distinctive characteristic of work-group mentality.

Within each group we observe ultimately a preparedness to engage with the psychic reality of the programme. Some were excited by this from the beginning, for others 
the journey was less comfortable. By the end, however, all were to a greater or lesser degree experiencing the psychic rewards of rising to the challenge and were appropriately proud of their contributions to the emergent strategy of the organisation.

For designers of leadership development programmes, this paper can contribute to a broadening in their thinking. Leaders are not tabula rasa. They are situated in their own organisational and other life contexts. Work challenges introduced through development programmes are bound to be considered in the frame of these other contexts. The competing demands from the different domains of one's life will influence the patterns of thoughts and actions that, in turn, influence the dynamics of attention and distraction. Designers of programmes should take a wider view of the likely responses to their designs.

For group facilitators, this paper raises awareness of the importance of the experiential nature of leadership programmes. Our experience suggests that there is a growing demand for these programmes to combine learning and 'real-life' application. In which case, the likelihood is that these programmes will edge into political and social spheres in and outside of the workplace - as this one did. It recommends a greater awareness of Bion's work, and specifically with an understanding of the contribution of his theory to the robustness of work-group mentality through a greater appreciation of the dynamics of attention and distraction. It also suggests that group facilitators build a capacity for Negative Capability in themselves and are attuned to its presence, or otherwise, in group members.

\section{Concluding Remarks}

The actual dynamic of any particular group is influenced by the capacity of its members to negotiate - consciously and unconsciously - the tension between these two opposed tendencies of attention and distraction: between the 'compulsion to develop' and 'the hatred of a process of development ... a hatred of having to learn by experience at all, and lack of faith in the worth of such a kind of learning.' (Bion, 1961, p. 89)

The case presented in this paper illustrates the danger of relating these mentalities to an actual group of people - as though one group with one set of characteristics may exhibit a compulsion to develop whilst another, with different characteristics, will resist development. On the contrary, all groups function influenced both by attention and by distraction, all groups possess both a love for and a hatred of learning. What may be of particular interest in the evolution of learning and development within a particular group is the manner in which the relationship between these two mentalities evolves. A different form of management is required in relation to each in order to facilitate progress in relation to the purpose and to specific tasks.

Attention or work-group mentality provides a space in which "thoughts" in search of a thinker' (Bion, 1967, p. 166) can be found and formed. Distraction or basicassumption mentality, by contrast, is deeply resistant to new thinking, so that individuals often complain that they 'cannot think' (Bion, 1961, p. 95). Indeed, one of the ways in which basic-assumption mentality may be identified in experience is the sense one can have of being unable to think or to find a new thought in the moment: 'Mental activity becomes stabilized on a level that is platitudinous, dogmatic, and 
painless. Development is arrested and the resultant stagnation is widespread.' (Bion, 1961, p. 128)

Finally, Bion was impressed by the radically different ways in which vitality is manifested in the two states. He writes of 'the vigour and vitality which can be mobilized by the work group' (Bion, 1961, p. 100). This is attained through sustained attention to the group purpose, which promotes development: 'In my experience the psychological structure of the work group is very powerful, and it is noteworthy that it survives with a vitality that would suggest that fears that the work group will be swamped by the emotional states proper to the basic assumptions are quite out of proportion'. (Bion, 1961, p. 98)

A group that is distracted from its purpose, dominated by basic-assumption mentality, by contrast produces only pseudo-vitality. Thus, when a group gives in to the wish 'to prevent development', by allowing itself 'to be overwhelmed by basic-assumption mentality', Bion notes that 'the main compensation for such a shift appears to be an increase in a pleasurable feeling of vitality' (Bion, 1961, p. 159). It does not last, however, being no more than 'a flicker of synthetic animation' (Bion, 1961, p. 144).

Whilst we observe the latter in the case under examination here, it is salutary to observe that Bion's essential optimism about work-group mentality is borne out in all three groups described in the case study. It is true that one group, which was significantly distracted from its purpose, did fracture severely and 'ejected' half of its members. However, it should be noted that the remnant still succeeded in addressing and completing its task. However, the most successful group was the one that sustained attention to purpose and demonstrated the strongest work-group function, influence by a strong friendship pairing. This, along with other aspects of Bion's notion of the work-group and its key forms of interaction, merits further study to complement the extensive work already undertaken on the phenomenon of basicassumption mentality and functioning.

\section{REFERENCES}

Armstrong, D. (2005) "The work group revisited: Reflections on the practice of group relations." In D. Armstrong, Organization in the mind: Psychoanalysis, group relations, and organizational consultancy - occasional papers 1989-2003, Ed. R. French. London: Karnac, pp. 139-50.

Bion, W.R. (1961) Experiences in groups and other papers. London: Tavistock Publications [reprinted London: Routledge, 1989; London: Brunner-Routledge, 2001].

Bion, W.R. (1962) Learning from Experience. London: W. Heinemann Medical Books.

Bion, W.R. (1967) Second thoughts. London: William Heinemann Medical Books [reprinted London: Karnac, 1989].

Bion, W.R. (1969) Cogitations. London: Karnac. 
Bion, W.R. (1978) Four Discussions with W.R. Bion. Strath Tay, Perthshire: Clunie Press.

Bion, W.R. (1984a). Attention and Interpretation, London: Karnac.

Bion, W.R. (1984b). Transformations, London: Karnac.

Eigen, M. (1981). 'The area of faith in Winnicott, Lacan and Bion' International Journal of Psycho-Analysis, 62: 413-33.

Eigen, M. (1993) The Electrified Tightrope. Northvale, New Jersey: Jason Aronson.

Eigen, M. (1998) The Psychoanalytic Mystic. London: Free Association Books.

Eigen, M. (2014) Faith. London: Karnac.

Eisold, K. (2005) ‘Using Bion’. Psychoanalytic Psychology, 22(3), 357-69.

French, R. (2001) 'Negative Capability': Managing the confusing uncertainties of change' Journal of Organizational Change Management, 14(5) 480-492.

French, R. and Simpson, P. (1999) “'Our Best Work Happens When We Don't Know What We're Doing'. Discuss.” Socio-Analysis, 1(2):216-230

French, R. and Simpson, P. (2001) Learning at the edges between knowing and notknowing: 'Translating' Bion. Organisational and Social Dynamics, 1(1), 54-77

French, R. and Simpson, P. (2010) “The 'Work Group': Redressing the Balance in Bion's Experiences in Groups.” Human Relations, 63(12): 1859-1878

French, R. and Simpson, P. (2014) Attention, purpose, cooperation. An approach to working in groups using insights from Wilfred Bion. London: Karnac.

Gilmore, T. (1999) 'Productive pairs' Briefing Note. Philadelphia: Center for Applied Research.

Lawrence, W.G., Bain, A. \& Gould, L. (1996) 'The fifth basic assumption.' Free Associations, 6, 28-55.

Lister, E. (2001) "Organizational change: tales of intergenerational and sibling rivalry", Journal of Organizational Change Management, 14(5): 468 - 480

Needleman, J. (1990) Lost Christianity: A Journey of Rediscovery to the Centre of Christian Experience. Shaftesbury, Dorset: Element Books.

Saggurthi , S. \& Thakur, M.K. (2016) Usefulness Of Uselessness : A Case For Negative Capability in Management. Academy of Management Learning and Education, 15(1): 180-193.

Seel, R. (2001) "Anxiety and incompetence in the large group", Journal of Organizational Change Management, 14 (5): 493 - 504 
Simpson, P. (1997) 'The place of faith in management learning', Management Learning, 28(4): 409-22.

Simpson, P., French, R. and Harvey, C.E. (2002) 'Leadership and negative capability', Human Relations, 55(10), 1209-26.

Simpson, P. and French, R. (2005) "Thoughtful Leadership. Lessons from Bion" Organisational and Social Dynamics, 5(2), 280-297

Simpson, P. \& French, R. (2006) "Negative Capability and the Capacity to Think in the Present Moment” Leadership, 2(2): 245-255

Simpson, P. (2010) "Engaging with the Unknowable through Narratives of Personal Experience" Journal of Organizational Change Management, 23(2): 173 - 179

Stein, M. and Pinto, J. (2011) 'The Dark Side of Groups: A "Gang at Work" in Enron’. Group \& Organization Management 36(6), 692-721.

Symington, J. \& Symington, N. (1996) The Clinical Thinking of Wilfred Bion. London: Routledge. 